\title{
Stability of Postannealed Silicon Dioxide Electret Thin Films Prepared by Magnetron Sputtering
}

\author{
Tadatsugu Minami ${ }^{1}$, Hidenobu Toda ${ }^{1}$,, Tetsuharu Utsubo ${ }^{1, *}$, Toshihiro Miyata ${ }^{1}$ \\ and Yoshiaki Ohbayashi ${ }^{2}$ \\ ${ }^{1}$ Optoelectronic Device System Research \& Development Center, Kanazawa Institute of Technology, Nonoichi, Ishikawa 921-8501, Japan \\ ${ }^{2}$ Technical \& Research Division, Hosiden Corporation, Yao 581-0071, Japan
}

The effect of postannealing on surface potential stability was investigated for silicon dioxide $\left(\mathrm{SiO}_{2}\right)$ electret thin films with a thickness of 2 to $5 \mu \mathrm{m}$. The $\mathrm{SiO}_{2}$ films were prepared on Al-coated and uncoated $\mathrm{Si}$ substrates by r.f. magnetron sputtering using a fused quartz target. Subsequent to the sputter deposition, the $\mathrm{SiO}_{2}$ films were postannealed in the deposition chamber in order to improve stability for use in a highly humid atmosphere. The obtained surface potential stability was dependent on not only the postannealing conditions but also the deposition conditions. The surface potential of $\mathrm{SiO}_{2}$ films postannealed in an oxidizing atmosphere at 275 to $350^{\circ} \mathrm{C}$ for 10 to 60 min was found to be highly stable when tested at a relative humidity of $90 \%$ and a temperature of $60^{\circ} \mathrm{C}$. In addition, the postannealed $\mathrm{SiO}_{2}$ films were stable for use in air for a long term at room temperature.

(Received December 27, 2001; Accepted April 15, 2002)

Keywords: electret, thin film, silicon dioxide, magnetron sputtering, postannealing, high surface potential stability, high relative humidity

\section{Introduction}

Electrets are of interest for use as dosimeters, acoustic transducers and microrelay switches as well as for the electrostatic anchoring of molecules in nanotechnology. ${ }^{1-8)}$ In addition, many recent developments involving the use of integrated and miniaturized device structures have required electret thin films prepared on substrates. ${ }^{7,8)}$ At present, organic polymers such as polytetrafluoroethylene (PTFE) and fluoroethylene propylene (FEP) are in practical use in most applications. However, it is very difficult to prepare suitable polymer electret thin films for many applications, because these organic materials with low melting points have difficulty withstanding the high temperature heat treatment processes involved in device fabrication. Recently, inorganic thin-film electret materials such as $\mathrm{SiO}_{2}$ and $\mathrm{Si}_{3} \mathrm{~N}_{4}$, with high melting points, have been investigated using various preparation methods as an alternative to organic polymers in many applications. ${ }^{9-14)}$ We have recently reported that $\mathrm{SiO}_{2}$ electret thin films prepared by conventional planar r.f. magnetron sputtering exhibited no surface potential decay when tested in air at room temperature for a long term. ${ }^{15)}$ The sputtered $\mathrm{SiO}_{2}$ thin films were stable even for use at a high temperature up to $230^{\circ} \mathrm{C}$. However, stability, or surface potential decay of the $\mathrm{SiO}_{2}$ films, was considerably affected by humidity. The decay in air at high relative humidity was significantly accelerated as the temperature was increased. We have recently found that the surface potential stability of sputtered $\mathrm{SiO}_{2}$ films could be improved by postannealing in an oxidizing atmosphere. ${ }^{15)}$

In this paper, we describe the effect of the deposition and postannealing conditions on the surface potential decay in air at high relative humidity: $\mathrm{SiO}_{2}$ electret thin films prepared by r.f. magnetron sputtering and postannealed in an oxidizing atmosphere.

\footnotetext{
${ }^{*}$ Graduate Student, Kanazawa Institute of Technology.
}

\section{Experimental Procedure}

$\mathrm{SiO}_{2}$ thin films with a thickness of 2 to $5 \mu \mathrm{m}$ were prepared on Al-coated and uncoated $\mathrm{Si}$ wafer substrates at a temperature of 250 to $350^{\circ} \mathrm{C}$ by conventional planar r.f. magnetron sputtering using a fused quartz target: target and substrate surface separation, $40 \mathrm{~mm}$. The sputter deposition was carried out in an $\mathrm{Ar}+\mathrm{O}_{2}$ mixed gas atmosphere at a pressure of 0.26 to $0.8 \mathrm{~Pa}$ with an r.f. power of $80 \mathrm{~W}: \mathrm{O}_{2}$ partial pressure varied from 4 to $20 \%$. A typical deposition rate of about $8 \mathrm{~nm} / \mathrm{min}$ was obtained with an r.f. power of $80 \mathrm{~W}$. The $\mathrm{SiO}_{2}$ films were annealed in the deposition chamber after the sputter deposition in order to improve stability in a highly humid atmosphere. The postannealing were carried out at a temperature of 250 to $350^{\circ} \mathrm{C}$ for 10 to $60 \mathrm{~min}$ in an oxidizing atmosphere. The oxidizing atmosphere in the deposition chamber was achieved by introducing an $\mathrm{Ar}+\mathrm{O}_{2}$ mixed gas at a flow rate of $20 \mathrm{sccm}$ after completion of the $\mathrm{SiO}_{2}$ film deposition. As a result, the gas pressure in the chamber gradually increased from 0.26 to about $655 \mathrm{~Pa}$ during a 60 min postannealing treatment.

The $\mathrm{SiO}_{2}$ films were electrically charged by a method utilizing the corona discharge resulting from a wire electrode and a grid electrode in air at room temperature (RT) with an applied voltage of $-5.3 \mathrm{kV}$. The negatively charged surface potential was varied by changing the voltage of the grid electrode as well as the distance between the grid electrode and the film surface. The resulting charged surface potential was dependent on the above charging conditions as well as the $\mathrm{SiO}_{2}$ film thickness. After being charged, an aging procedure was performed; all charged $\mathrm{SiO}_{2}$ films were heat-treated for $1 \mathrm{~h}$ in air at $150^{\circ} \mathrm{C}$ in order to stabilize the initial surface potential $\left(V_{\mathrm{IN}}\right)$ of the charged films prior to testing. However, after being heat-treated, the level of surface potential (or $V_{\mathrm{IN}}$ ) was also dependent on the surface potential stability or decay of the charged $\mathrm{SiO}_{2}$ films during the heat treatment. The surface potential stability of $\mathrm{SiO}_{2}$ electret films in high rela- 
tive humidity was evaluated using either the measured surface potential $(V)$ or the normalized surface potential $\left(V / V_{\mathrm{IN}}\right)$.

\section{Results and Discussion}

\subsection{Stability of postannealed films}

The surface potential of $\mathrm{SiO}_{2}$ electret films prepared under optimized deposition conditions by r.f. magnetron sputtering was found to exhibit no decay when tested in air at room temperature (RT) for a long term. Nevertheless, the surface potential decay in air at high relative humidity was significantly accelerated as the temperature was increased, as shown in Fig. 1. On the other hand, we have recently found that the surface potential stability of $\mathrm{SiO}_{2}$ electret films at high relative humidity could be improved by postannealing in an oxidizing atmosphere; i.e., the obtained potential stability was significantly affected by both the deposition conditions and the postannealing conditions of the $\mathrm{SiO}_{2}$ films. As an example, the potential decay in a highly humid atmosphere is shown in Fig. 2 for $\mathrm{SiO}_{2}$ films postannealed at a temperature of $350^{\circ} \mathrm{C}$ for $60 \mathrm{~min}$ in an $\mathrm{Ar}+\mathrm{O}_{2}(20 \%)$ mixed gas atmosphere; the surface potential decay of as-deposited and postannealed $\mathrm{SiO}_{2}$ films prepared at an $\mathrm{O}_{2}$ partial pressure of 4 and $8 \%$ can be compared. It should be noted that the surface potential stability in air at a temperature of $60^{\circ} \mathrm{C}$ and a relative

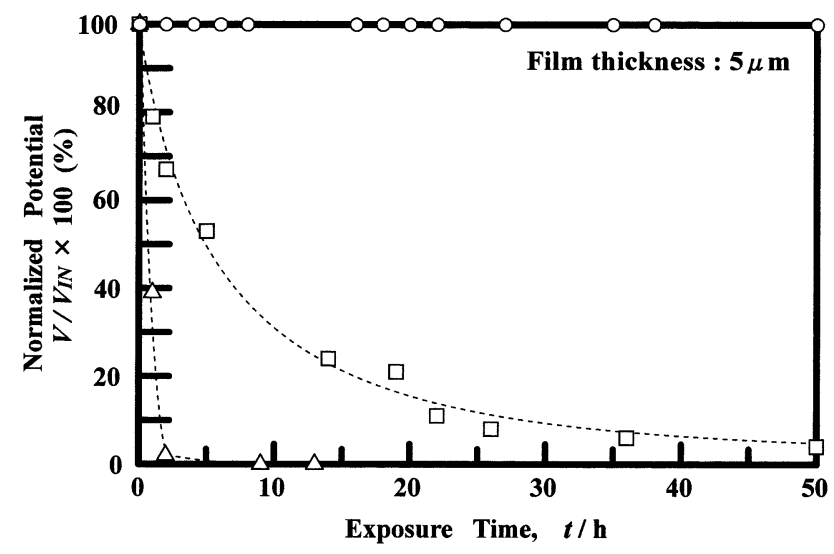

Fig. 1 Decay of normalized surface potential of $\mathrm{SiO}_{2}$ films tested under various conditions: in air at $\mathrm{RT}(\bigcirc)$; at $60^{\circ} \mathrm{C}, 90 \%(\square)$; and at $80^{\circ} \mathrm{C}, 90 \%$ $(\triangle)$.

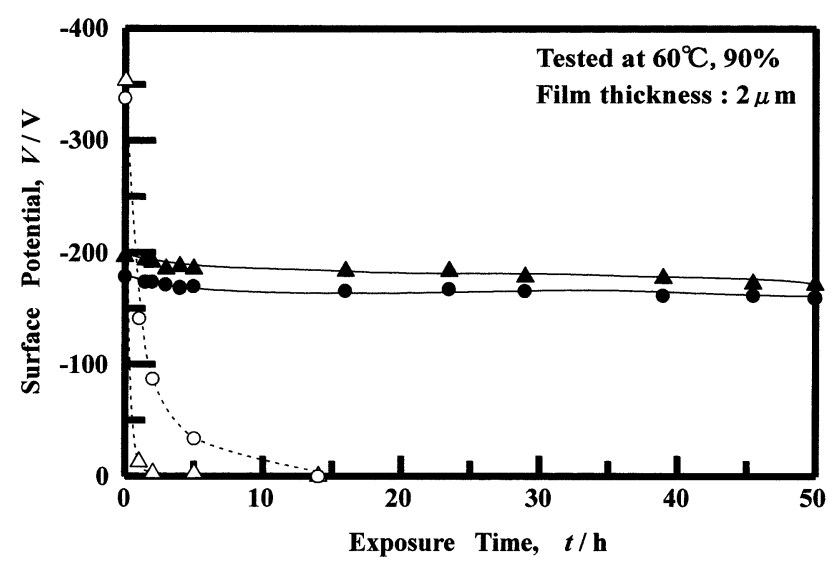

Fig. 2 Surface potential decay of as-deposited (open) and postannealed (closed) $\mathrm{SiO}_{2}$ films prepared at $\mathrm{O}_{2}$ partial pressures of $4 \%(\mathrm{O}, \boldsymbol{O})$ and $8 \%(\triangle, \mathbf{\Delta})$. humidity of $90 \%$ was improved by postannealing; it was also dependent on the r.f. magnetron sputtering deposition conditions. It should be noted that this improvement in potential stability was not obtained when the $\mathrm{SiO}_{2}$ films were moved from the deposition chamber into air before being postannealed. In contrast, it was found that the surface potential stability of postannealed $\mathrm{SiO}_{2}$ electret films was relatively independent of film thickness in the range of 2 to $5 \mu \mathrm{m}$, whereas $V_{\mathrm{IN}}$ increased as the thickness was increased. Figure 3 shows typical surface potential decay for postannealed electret $\mathrm{SiO}_{2}$ films prepared with a thickness of 2 and $5 \mu \mathrm{m}$ and tested at a temperature of $60^{\circ} \mathrm{C}$ and a relative humidity of $90 \%$.

\subsection{Deposition condition dependence of stability}

In order to evaluate the surface potential stability of $\mathrm{SiO}_{2}$ electret films in a highly humid atmosphere, the following surface potential decay tests were conducted in air at a temperature of $60^{\circ} \mathrm{C}$ and a relative humidity of $90 \%$. Figure 4 shows surface potential decay as a function of $\mathrm{O}_{2}$ partial pressure for $\mathrm{SiO}_{2}$ films prepared at a sputter gas pressure of $0.26 \mathrm{~Pa}$ and a temperature of $350^{\circ} \mathrm{C}$ and postannealed at $350^{\circ} \mathrm{C}$ for $60 \mathrm{~min}$ in an $\mathrm{Ar}+\mathrm{O}_{2}(20 \%)$ gas atmosphere; the resulting high stability was not significantly affected by an oxygen partial pressure from 4 to $20 \%$.

Figure 5 shows surface potential decay as a function of sputter gas pressure for $\mathrm{SiO}_{2}$ films prepared in an $\mathrm{Ar}+\mathrm{O}_{2}$ $(8 \%)$ sputter gas at $350^{\circ} \mathrm{C}$ and postannealed at $350^{\circ} \mathrm{C}$ for

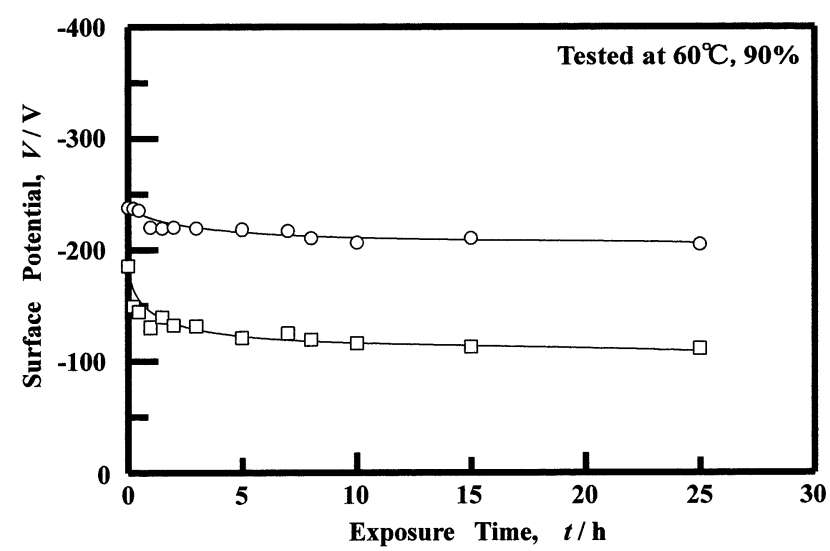

Fig. 3 Surface potential decay of postannealed $\mathrm{SiO}_{2}$ films with a film thickness of $2(\square)$ and $5(\bigcirc) \mu \mathrm{m}$.

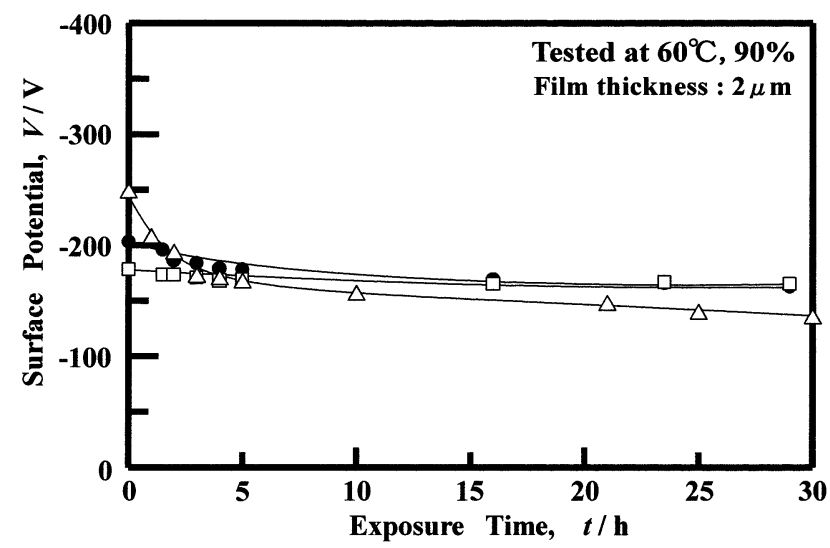

Fig. 4 Surface potential decay of postannealed $\mathrm{SiO}_{2}$ films prepared at a $\mathrm{O}_{2}$ partial pressure of $4 \%(\square), 8 \%(\bullet)$ and $20 \%(\triangle)$. 


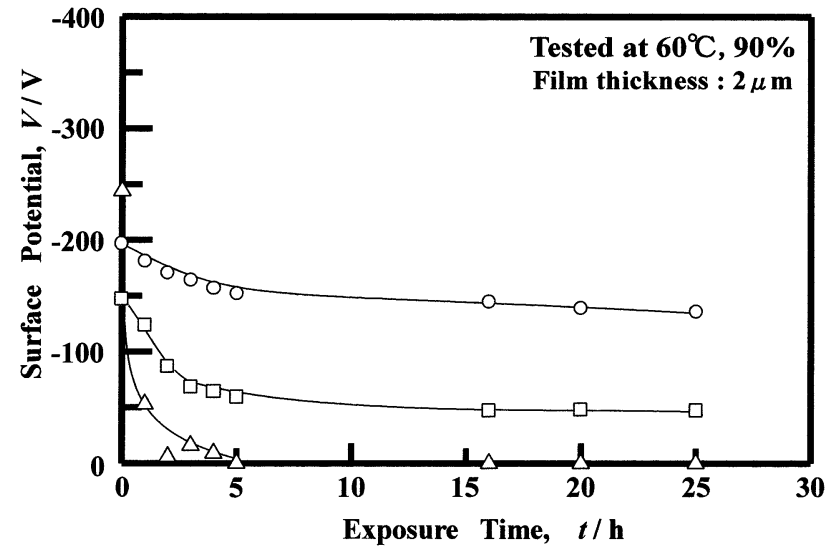

Fig. 5 Surface potential decay of postannealed $\mathrm{SiO}_{2}$ films prepared at a sputter gas pressure of $0.26(\bigcirc), 0.4(\square)$ and $0.8(\triangle) \mathrm{Pa}$.

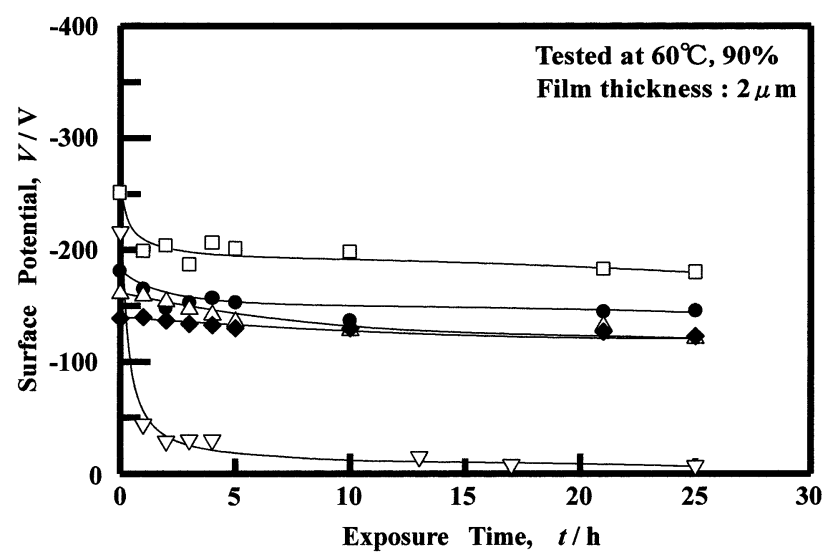

Fig. 6 Surface potential decay of postannealed $\mathrm{SiO}_{2}$ films prepared at a deposition temperature of $250^{\circ} \mathrm{C}(\nabla), 275^{\circ} \mathrm{C}(\diamond), 300^{\circ} \mathrm{C}(\triangle), 325^{\circ} \mathrm{C}(\square)$ and $350^{\circ} \mathrm{C}(\mathbf{O})$

$60 \mathrm{~min}$ in an $\mathrm{Ar}+\mathrm{O}_{2}(20 \%)$ gas atmosphere. It should be noted that the surface potential stability decreased as the sputter gas pressure was increased. The sputter gas pressure producing the best result was $0.26 \mathrm{~Pa}$, the lowest pressure available for r.f. magnetron sputtering used in this work. Surface potential decay as a function of deposition temperature is shown in Fig. 6 for $\mathrm{SiO}_{2}$ electret films prepared at a pressure of $0.26 \mathrm{~Pa}$ in $\mathrm{Ar}+\mathrm{O}_{2}(8 \%)$ sputter gas and postannealed at $350^{\circ} \mathrm{C}$ for $60 \mathrm{~min}$ in an $\mathrm{Ar}+\mathrm{O}_{2}(20 \%)$ gas atmosphere. The surface potential of $\mathrm{SiO}_{2}$ films deposited at a temperature of 275 to $350^{\circ} \mathrm{C}$ was stable; the potential stability is relatively independent of the deposition temperature. However, the decay of the film deposited at $250^{\circ} \mathrm{C}$ was considerably faster than that of films deposited at temperatures above about $275^{\circ} \mathrm{C}$.

\subsection{Postannealing condition dependence of stability}

Figure 7 shows surface potential decay as a function of postannealing time for $\mathrm{SiO}_{2}$ films prepared in $\mathrm{Ar}+\mathrm{O}_{2}(8 \%)$ sputter gas at $350^{\circ} \mathrm{C}$ and a sputter gas pressure of $0.26 \mathrm{~Pa}$ and postannealed at $350^{\circ} \mathrm{C}$ in an $\mathrm{Ar}+\mathrm{O}_{2}(20 \%)$ gas atmosphere. The stability of $\mathrm{SiO}_{2}$ electret films was relatively independent of the postannealing time in the range of 10 to $60 \mathrm{~min}$, whereas the level of surface potential decreased as the postannealing time was increased. Figure 8 shows typical surface potential decay for $\mathrm{SiO}_{2}$ films prepared in $\mathrm{Ar}+\mathrm{O}_{2}(8 \%)$ sputter gas at $350^{\circ} \mathrm{C}$ and a sputter gas pressure of $0.26 \mathrm{~Pa}$ and

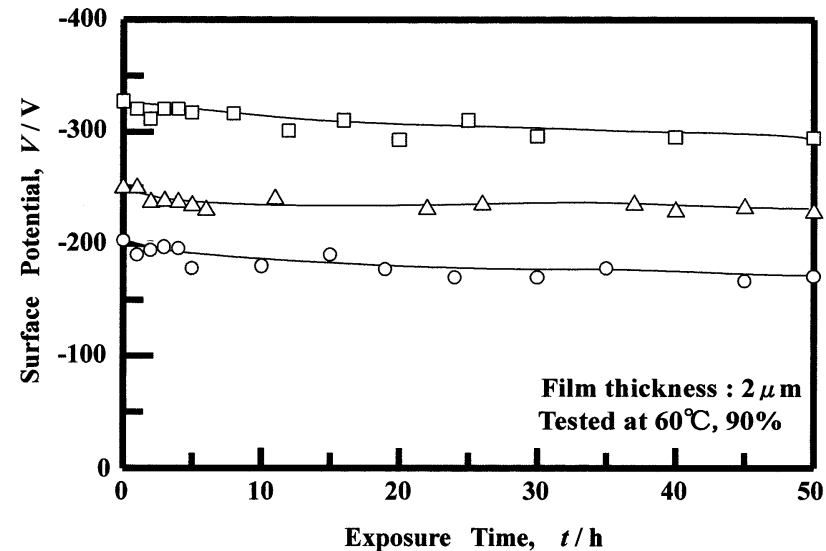

Fig. 7 Surface potential decay of $\mathrm{SiO}_{2}$ films postannealed for 10 ( $\square$ ), 30 $(\triangle)$ and $60(\bigcirc) \mathrm{min}$.

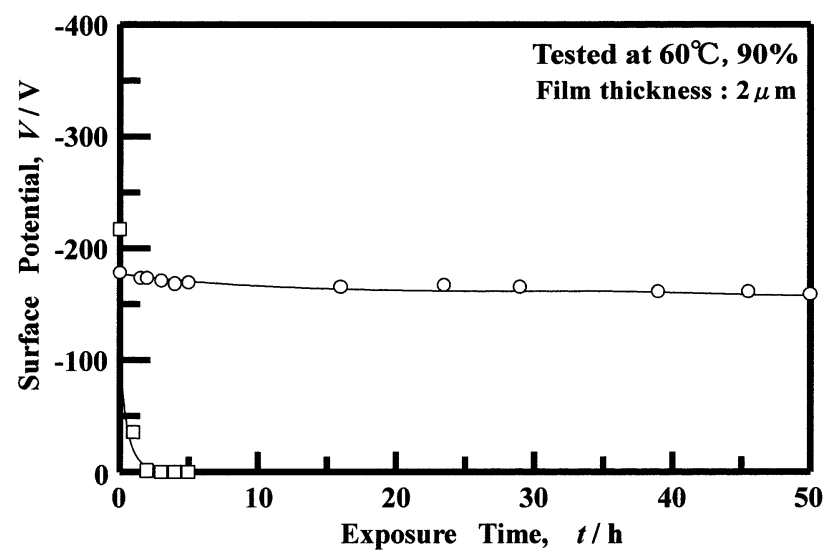

Fig. 8 Surface potential decay of $\mathrm{SiO}_{2}$ films postannealed at a temperature of $250^{\circ} \mathrm{C}(\square)$ and $350^{\circ} \mathrm{C}(\bigcirc)$.

postannealed at 250 and $350^{\circ} \mathrm{C}$ for $60 \mathrm{~min}$ in an $\mathrm{Ar}+\mathrm{O}_{2}$ (20\%) gas atmosphere. It should be noted that the $\mathrm{SiO}_{2}$ film postanealed at $250^{\circ} \mathrm{C}$ was unstable when tested in air at a temperature of $60^{\circ} \mathrm{C}$ and a relative humidity of $90 \%$. The stability was considerably affected by the postannealing temperature; high stability was obtained in postannealed $\mathrm{SiO}_{2}$ films postannealed in the temperature range of approximately 275 to $350^{\circ} \mathrm{C}$.

\subsection{Effects of postannealing}

As mentioned above, a highly stable surface potential at high relative humidities could be obtained in $\mathrm{SiO}_{2}$ films prepared by r.f. magnetron sputtering and postannealed in the deposition chamber. However, high stability in air for a long term at RT is also required for practical applications. The surface potential of $\mathrm{SiO}_{2}$ electret films postannealed under the optimal condition was relatively stable for use in air at RT. The surface potential decay shown in Fig. 9 compares an as-deposited with a postannealed $\mathrm{SiO}_{2}$ film: postannealing at $350^{\circ} \mathrm{C}$ for $60 \mathrm{~min}$ in an $\mathrm{Ar}+\mathrm{O}_{2}(20 \%)$ gas atmosphere. It should be noted that postannealing improved the surface potential stability of $\mathrm{SiO}_{2}$ films in air for a long term not only at RT but also at a relative humidity of $90 \%$ and a temperature of $60^{\circ} \mathrm{C}$.

In order to clarify the mechanism causing the improvement in surface potential stability, differences in chemical structure 


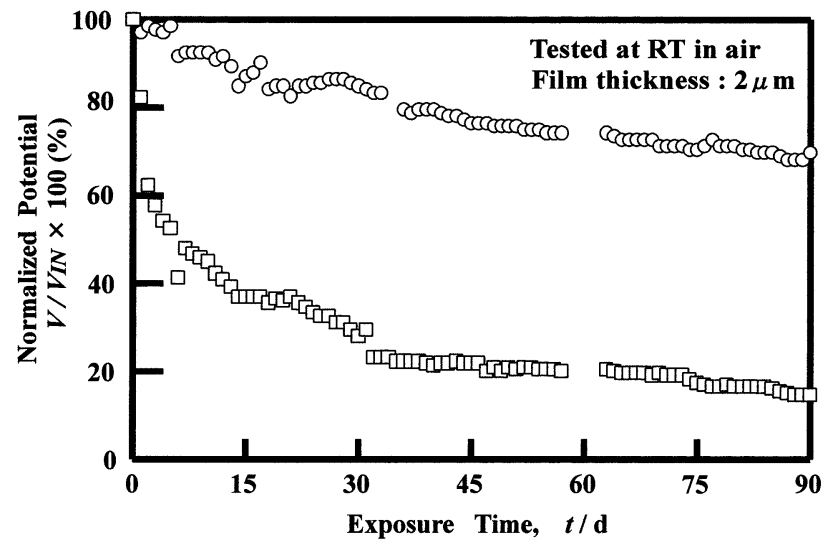

Fig. 9 Decay in normalized surface potential of as-deposited $(\square)$ and postannealed $(\mathrm{O}) \mathrm{SiO}_{2}$ films tested in air at $\mathrm{RT}$.

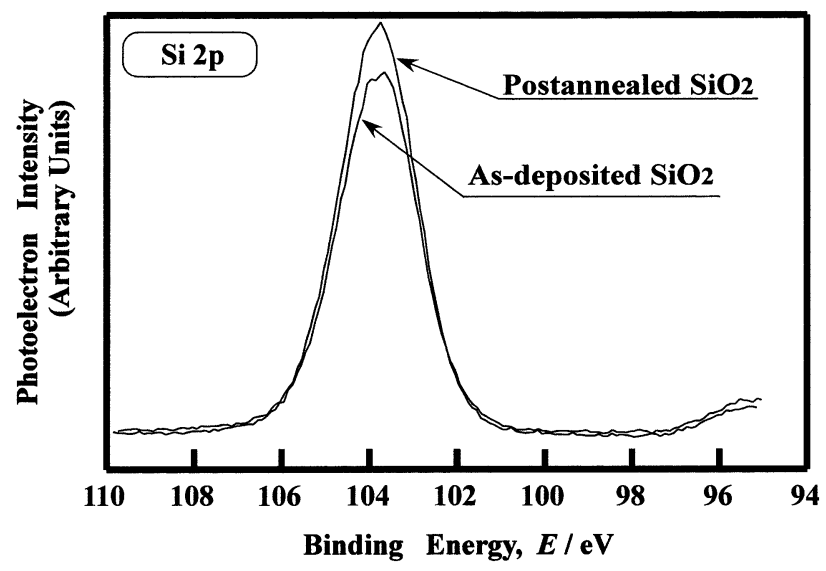

Fig. $10 \mathrm{Si} 2 \mathrm{p}$ XPS spectra of as-deposited and postannealed $\mathrm{SiO}_{2}$ films.

between as-deposited and postannealed $\mathrm{SiO}_{2}$ films were investigated using x-ray photoelectron spectroscopy (XPS) and Fourier transformation infrared (FTIR) spectroscopy. Figure 10 shows the Si 2 p core-level XPS spectra obtained from asdeposited and postannealed $\mathrm{SiO}_{2}$ films. Both types of film exhibited the same spectrum consisting of a single peak at $104 \mathrm{eV}$. It is widely accepted that the $\mathrm{Si}^{4+}$ chemical state of the $\mathrm{Si}$ atom corresponds to the peak at approximately $104 \mathrm{eV}$ : a Si atom bonding to four oxygen atoms, resulting in an average composition ratio of $\mathrm{Si} / \mathrm{O}=1 / 2$.

The absorption spectra obtained by FTIR measurements comparing as-deposited (a) and postannealed $\mathrm{SiO}_{2}$ films (b) are shown in Fig. 11. It should be noted that as-deposited and postannealed $\mathrm{SiO}_{2}$ films exhibited the same absorption spectrum consisting of three main peaks. The three absorption peaks at approximately 1110,820 and $450 \mathrm{~cm}^{-1}$ are attributed to $\mathrm{Si}-\mathrm{O}$ stretching, bending and rocking vibrations, respectively. ${ }^{16,17)}$ The $\mathrm{Si}-\mathrm{O}$ stretching band can be roughly disassociated into two distinctive Gaussian peaks at approximately 1070 and $1180 \mathrm{~cm}^{-1} \cdot{ }^{16,18,19)}$ The broad half-band width of these peaks may suggest $\mathrm{SiO}_{2}$ composed of $\mathrm{Si}-\mathrm{O}$ molecules with various bond lengths, i.e., a lot of structural defects. ${ }^{18,19)}$ In Fig. 11, it should be noted that the intensity of the absorption peak around $1070 \mathrm{~cm}^{-1}$, resulting from $\mathrm{Si}-\mathrm{O}$ stretching vibrations, is lower than the absorption peaks reported in most FTIR data. However, the postannealing effect may not be attributable to differences in structural defects between the $\mathrm{SiO}_{2}$

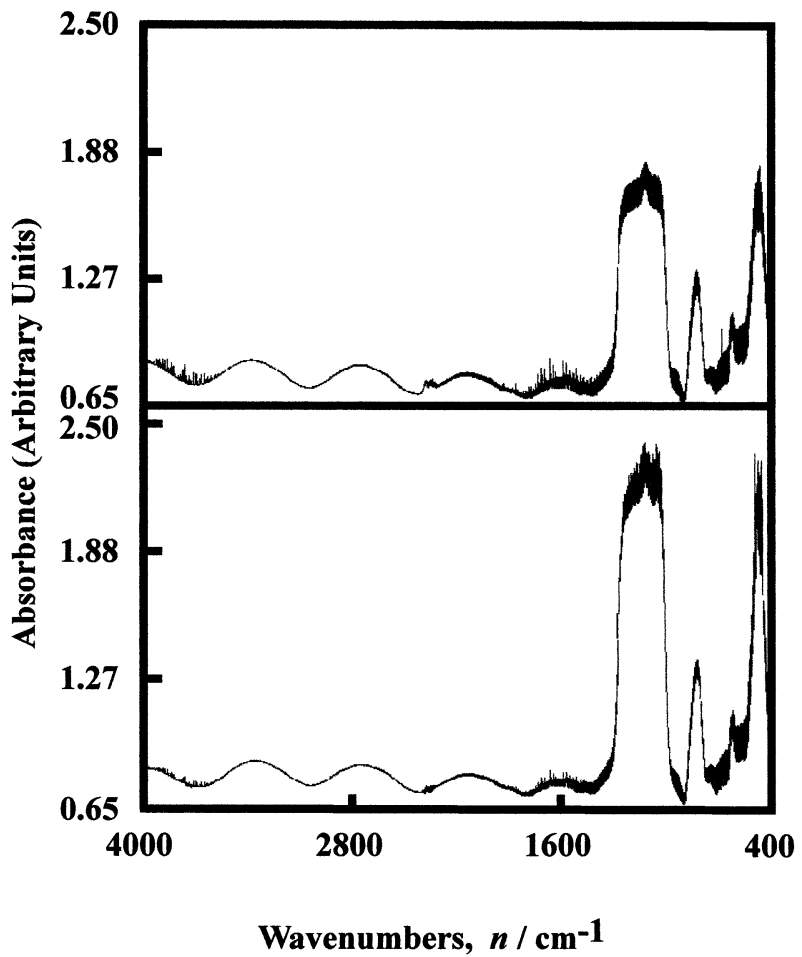

Fig. 11 Infrared absorption spectra of as-deposited (a) and postannealed (b) $\mathrm{SiO}_{2}$ films.

films.

\section{Conclusions}

High surface potential stability at high relative humidity was realized in silicon dioxide $\left(\mathrm{SiO}_{2}\right)$ electret thin films prepared by r.f. magnetron sputtering using a fused quartz target. Postannealing was needed to obtain high potential stability in air at a relative humidity of $90 \%$; the potential decay of asdeposited $\mathrm{SiO}_{2}$ films was significantly accelerated as the temperature was increased from RT. After the $\mathrm{SiO}_{2}$ films were deposited on Al-coated and uncoated Si substrates at a temperature of 275 to $350^{\circ} \mathrm{C}$, the films were postannealed in an oxidizing atmosphere at 275 to $350^{\circ} \mathrm{C}$ for 10 to $60 \mathrm{~min}$. The obtainable stability was considerably affected by not only the postannealing conditions but also the deposition conditions of the $\mathrm{SiO}_{2}$ films. However, investigation have not shown any clear differences in the chemical structure of as-deposited and postannealed $\mathrm{SiO}_{2}$ films. High surface potential stability at a relative humidity of $90 \%$ and a temperature of $60^{\circ} \mathrm{C}$ was obtained for postannealed $\mathrm{SiO}_{2}$ electret films. In addition, high stability in air for a long term at RT was realized in postannealed $\mathrm{SiO}_{2}$ electret films.

\section{Acknowledgments}

The authors would like to thank K. Nakajima and R. Yamazaki for their technical assistance in the experiments.

\section{REFERENCES}

1) G. M.Sessler: Electrets, (Springer, Berlin, 33 1987).

2) G. M.Sessler: Proc. of 15th Int. Congress on Acoustics, (1995) pp. 253- 
260.

3) H. Amjadi and C. Thielemann: IEEE Transaction on Dielectrics and Electrical Insulation 3 (1996) 494-498.

4) C.Thielemann and G.Hess: Sensor and Actuators A61 (1997) 352-355.

5) W. M. D. Wright and D. G. Chetwynd: Nanotechnology 9 (1998) 133142.

6) G. M. Sessler and R. Gerard-Multhaupt: ed.: Electrets, (Laplacian Press, 1999).

7) R. G. Multhaupt: Electrets in Wiley Encyclopedia of Electrical and Electronics Engneering 6 (1999) 220-229.

8) R. Schwdiauer, G. S. Neugschwandtner, S. B. Gogonea and S. Bauer: Appl. Phys. Lett. 75 (1999) 3998-4000.

9) D. Hohm and R. G. Multhaupt: J. Acoust. Sco. Am. 75 (1984) 12971298.

10) P. Gunther: IEEE Transaction on Electrical Insulation 24 (1989) 439442.

11) P. Gunther and Z. Xia: J. Appl. Phys. 74 (1993) 7269-7274.
12) J. E. K. Sapieha, L. Martinu, M. R. Wertheimer, P. Gunther, R. Schellin, C. Thielemann and G. M.Sessler: J. Vac. Sci. Technol. A14 (5) (1996) 2775-2779.

13) M. Ichiya, T. Nakamura, S. Nakata and J. Lewiner: IEICE Trans. Electron. E-79C (1996) 1462-1466.

14) M. Ichiya, T. Nakamura, S. Nakata and J. Lewiner: IEICE Trans. Electron. E-80C (1997) 174-182.

15) T. Minami, H. Toda, T. Utsubo and T. Miyata: Proc. of 4th Pacific Rim Inter. Conf. on Advanced Materials and Processing, to be published.

16) G. Lucovsky, J. Yang, S. S. Chao, J. E. Tyler and W. Czubatyj: Phys. Rev. B 28 (1983) 3225-3233.

17) L. He, T. Inokuma, Y. Kurata and S. Hasegawa: J. Non-Cryst. Solids 185 (1995) 249-261.

18) J. S. Chou and S. C. Lee: J. Appl. Phys. 77 (1995) 1805-1807.

19) N. Primeau, C. Vautey and M. Langlet: Thin Solid Films 310 (1997) $47-56$. 